\title{
Hydrogen Uptake Enhancement by the Use of a Magnesium Hydride and Carbon Nanotubes Mixture
}

\author{
Rodrigo Bezerra Vasconcelos Campos ${ }^{a}$, Sergio Alvaro de Souza Camargo Junioo ${ }^{a, b}$, Mariana \\ Coutinho Brum ${ }^{b}$, Dilson Silva dos Santos ${ }^{a, b}$
}

\begin{abstract}
aPrograma de Engenharia de Nanotecnologia, Instituto Alberto Luiz Coimbra de Pós-Graduação e Pesquisa em Engenharia - COPPE, Universidade Federal do Rio de Janeiro - UFRJ, P.O Box 68505, Rio de Janeiro, RJ, Brazil

${ }^{b}$ Departamento de Engenharia Metalúrgica e de Materiais, Instituto Alberto Luiz Coimbra de PósGraduação e Pesquisa em Engenharia - COPPE, Universidade Federal do Rio de Janeiro - UFRJ, P.O

Box 68505, Rio de Janeiro, RJ, Brazil
\end{abstract}

Received: April 30, 2017; Revised: September 03, 2017; Accepted: October 25, 2017

\begin{abstract}
Studies show that the carbon nanotubes (CNTs) serve as hydrogen diffusion channels, when used with magnesium hydride. The hydrogen sorption study, of a $\mathrm{MgH}_{2}$ and $5 \mathrm{wt} \%$ of multiwalled carbon nanotubes mixture, was the main purpose of this work. The samples were analyzed by means of X-ray diffraction (XRD) and also studied in a differential scanning calorimeter (DSC). The carbon nanotubes, that were ball milled during $20 \mathrm{~min}$ to the $\mathrm{MgH}_{2}$ were observed in the scanning electron microscopy (SEM) images. The mixture of $\mathrm{MgH}_{2}-\mathrm{CNT}$ turned out to enhance the hydrogen sorption when compared to pure $\mathrm{MgH}_{2}$ and in $5 \mathrm{~min}$ it desorbed around $5 \mathrm{wt} \%$ of hydrogen, at $350^{\circ} \mathrm{C}$ and $0.1 \mathrm{bar}$.
\end{abstract}

Keywords: hydrogen storage, carbon nanotubes, ball milling, magnesium hydride.

\section{Introduction}

Nanomaterials have been thoroughly studied regarding energy storage in the past years ${ }^{1,2}$

When it comes to studying these nanomaterials with magnesium, some recent and interesting results were obtained in the past decade, especially with carbon nanotubes ${ }^{3,4,5}$ Magnesium is chosen because of its low cost and abundance. However, the use of magnesium for hydrogen storage presents some limitations such as slow kinetics and high operation temperatures. A nanomaterial such as carbon nanotube (CNT) is milled to magnesium to help overcome those limitations aforementioned ${ }^{6-11}$. Researchers agree that carbon nanotubes can act as a catalyst enhancing hydrogen uptake but the sorption mechanism is still not fully understood ${ }^{8}$. The type of CNT chosen for this work was the multi-walled carbon nanotube (MWCNT) and magnesium hydride $\left(\mathrm{MgH}_{2}\right)$ was used to be milled to the catalyst. The comparison of the results found in this work with others performed previously that use other types of materials ${ }^{13,14}$ that have a one-dimensional morphology could help shed a light on the mechanism involved in the hydrogen sorption.

\section{Experimental}

Multi-walled carbon nanotubes (MWCNTs), with diameters ranging from 5 to $60 \mathrm{~nm}$ and lengths ranging from 5 to $30 \mathrm{~mm}$, were supplied by CT Nanotubos (Federal University of Minas Gerais). This material has 95\% purity

*e-mail: rvasconcelos@metalmat.ufrj.br and controlled size distribution. Magnesium hydride $\left(\mathrm{MgH}_{2}\right)$ was supplied by Sigma-Aldrich and submitted to ball milling with tungsten carbide balls under $\mathrm{H}_{2}$ atmosphere for 24 hours at 300 rpm using a Fritsch P-6 planetary mill. After that, the $\mathrm{MgH}_{2}$ was milled for 20 minutes more with 5 wt. (\%) of carbon nanotube. The samples were handled in a glove box under argon atmosphere. The $\mathrm{MgH}_{2}-\mathrm{CNT}$ morphology was analyzed by using scanning electron microscopy (SEM-JEOL JSM 6460LV). X-ray diffraction analysis were performed in a Bruker- G8 Discovery equipment. A differential scanning calorimeter (DSC-Setaram) was used to investigate the hydride phase stability under argon atmosphere. The kinetics tests were performed by an automatic Sievert's type apparatus designed by PCT-Pro 2000. The hydrogen absorption and desorption measurements were performed at 20 bar and 0.1 bar of hydrogen pressure, respectively, at 300 and $350{ }^{\circ} \mathrm{C}$.

\section{Results and Discussion}

The scanning microscopy (SEM) micrograph, Fig. 1, shows an agglomerate of small particles with size ranging from nanometers to micrometers. The multi-walled carbon nanotubes (MWCNT) combined to magnesium hydride $\mathrm{MgH}_{2}$ can be seen. Since ball milling can be detrimental to some catalysts such as carbon nanotubes ${ }^{12}$, it was performed for only $20 \mathrm{~min}$. Although a thorough investigation on ball milling conditions is still needed, for the present research, the fact that the MWCNT appear as their original morphology on the SEM image is an interesting finding. 


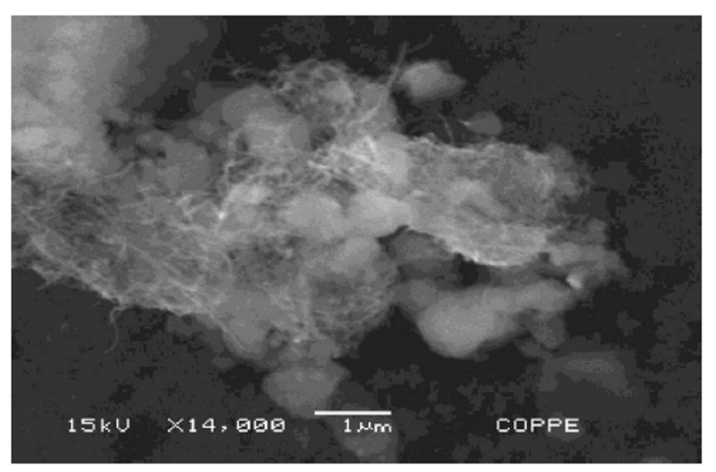

Figure 1. SEM image of $\mathrm{MgH} 2$ milled with $5 \mathrm{wt} \%$ MWCNT for $20 \mathrm{~min}$

In Fig. $2 b$, the $\beta$ and $\gamma$ peaks for $\mathrm{MgH}_{2}$ due to grinding are shown for the $\mathrm{MgH}_{2}$ milled with $5 \mathrm{wt} \%$ MWCNT pattern. The MWCNTs peaks were not detected because of their low abundance.The DSC result shown in Fig. 3 were obtained at a heating rate of $10^{\circ} \mathrm{C} \mathrm{min}^{-1}$, for $\mathrm{MgH}_{2}$ milled for 24 hours ${ }^{14}$ and after being milled for 20 min with MWCNT catalyst. The curve shows two endothermic peaks which correspond to the $\beta$ and $\gamma \mathrm{MgH}_{2}$ phases, which were seen previously in the XRD patterns (Fig. 2). The hydride decomposition temperature is $370{ }^{\circ} \mathrm{C}$. This temperature is lower than the values obtained for pure $\mathrm{MgH}_{2}$ between 400 and $450^{\circ} \mathrm{C}^{13,14}$ because of the presence of the catalyst.

a)

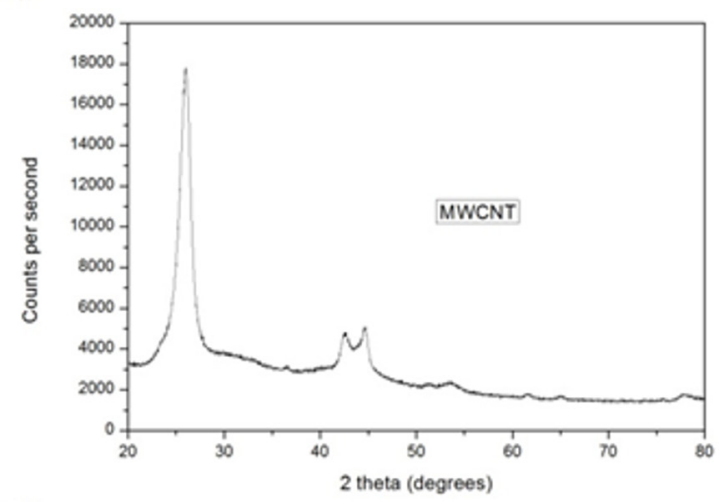

b)

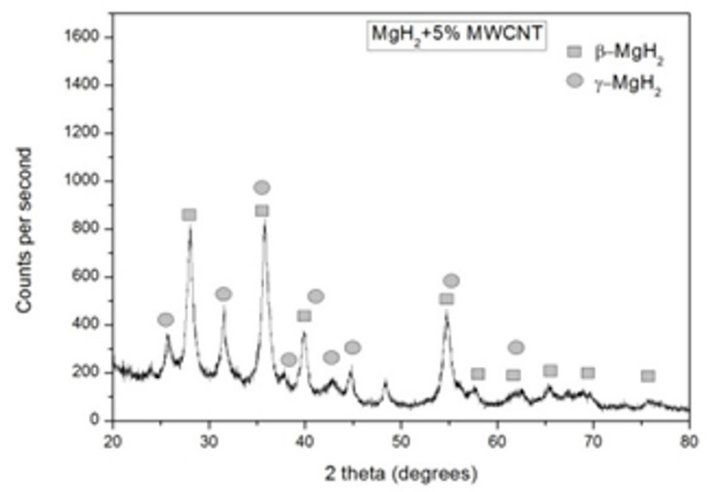

Figure 2. XRD patterns of multi-walled carbon nanotubes and $\mathrm{MgH} 2$ milled for 20 min with MWCNT Only

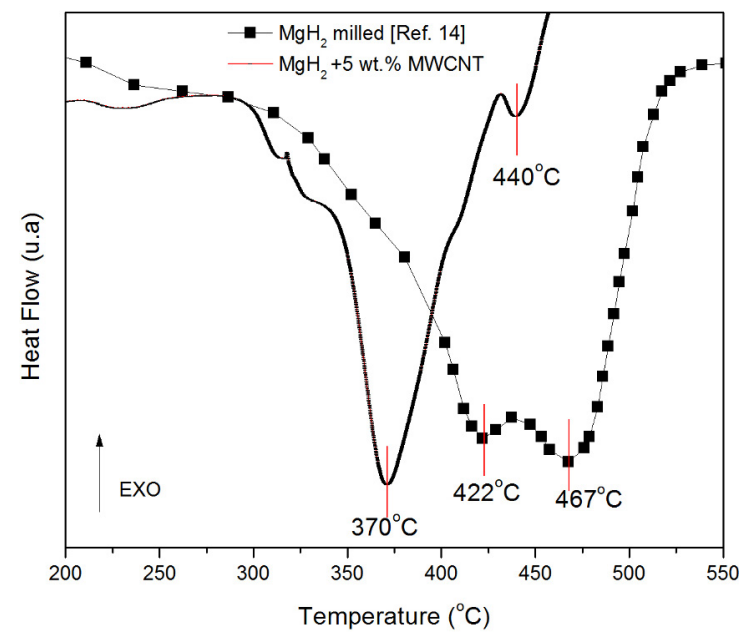

Figure 3. The DSC curves (heating rate $10{ }^{\circ} \mathrm{C} / \mathrm{min}$ ) for the sample $\mathrm{MgH} 2+5 \mathrm{wt} \% \mathrm{MWCNT}$ and $\mathrm{MgH} 2$ milled for 24 hours.

The absorption/desorption kinetic curves are shown in Fig. $4 \mathrm{a}$ and Fig.4b, respectively. The absorption kinetic results do not show a significant change on the hydrogen uptake when varying the temperature from $300^{\circ} \mathrm{C}$ to $350^{\circ} \mathrm{C}$, Fig4a. The absorption results are in accordance to the ones obtained in the literature for $\mathrm{Mg}-5 \mathrm{wt} \% \mathrm{MWCNT}$, at $300^{\circ} \mathrm{C}$, since the hydrogen uptake was almost $4.0 \mathrm{wt} \%$ at $2 \mathrm{~min}^{10}$. However, the pressure used in the kinetic tests were higher than those used in the present work.

The plateau was attained in $2.5 \mathrm{~min}$, at $350{ }^{\circ} \mathrm{C}$, for $\mathrm{MgH}_{2}+5 \mathrm{wt} \% \mathrm{MWCNT}$ and the maximum hydrogen uptake was around $5 \mathrm{wt} \%$, Fig. $4 \mathrm{~b}$ at $350{ }^{\circ} \mathrm{C}, 0.1$ bar.

Previous work performed with $\mathrm{MgH}_{2}$ milled with onedimensional (1-D) niobium based catalsysts, and other work with $\mathrm{TiO}_{2}$ based 1D nanomaterial ${ }^{13,14}$ are shown in Figure 5 along with the one obtained in the present work for MWCNT. The experimental conditions were the same to prepare the sample and the temperature used to conduct the kinetic tests was $350^{\circ} \mathrm{C}$. The difference between the amount of absorbed and desorbed hydrogen is the result of an already expected experimental error. The hydrogen uptake value obtained for these samples with $\mathrm{MgH}_{2}$ are between 5.0 and $6.0 \mathrm{wt} \%$. Besides the catalytic properties of those three types of materials, it seems as if the one-dimensional morphology facilitates the hydrogen diffusion. The effects of using different carbon materials on $\mathrm{MgH}_{2}$ decomposition was studied and carbon nanotubes showed better results than graphite and activated carbon that to not have a 1-D morphology and therefore contributes to interpret these findings ${ }^{6}$.

Other studies also investigated the results of the addition of MWCNT to $\mathrm{MgH}_{2}{ }^{15,16}$. The conditions of ball milling, temperature and pressure are determining factors for the kinetics and absorption capacity of the composite material. Lototskyy et. al. ${ }^{15}$ observed a high capacity of 6 to $7 \%$ of $\mathrm{MgH}_{2}+\mathrm{MWCNT}$ ( 1 to $5 \%$ ) during high energy reactive ball milling (HRBM). These values were reached after a long grinding time and under more energetic conditions 
a)

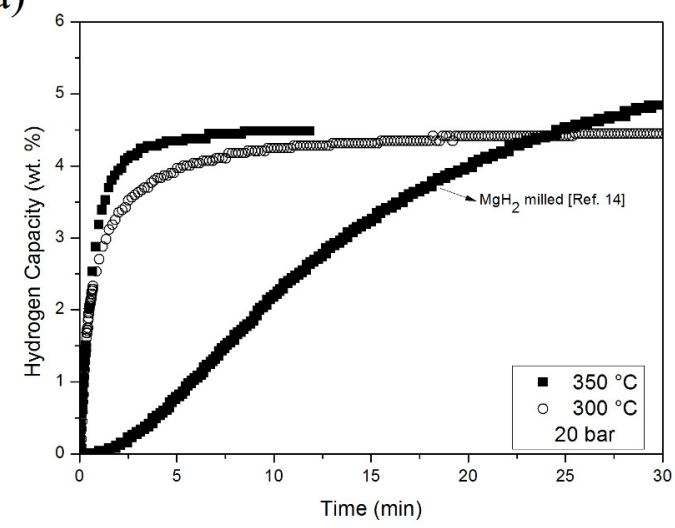

b)

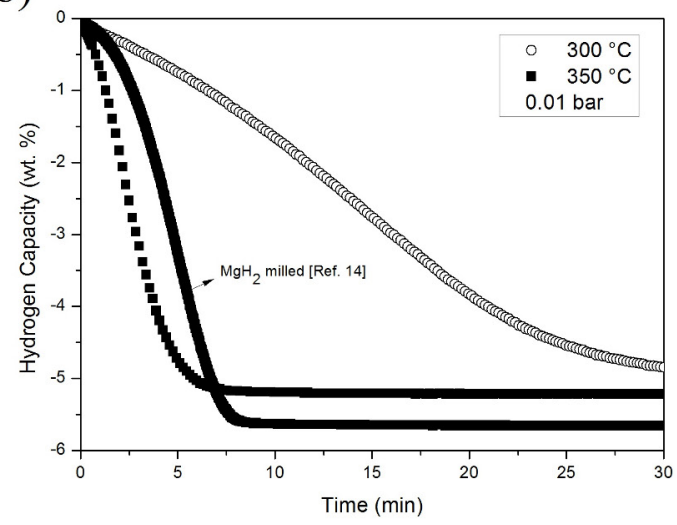

Figure 4. Hydrogen absorption (a) and desorption curves (b) of $\mathrm{MgH} 2$ milled for 24 hours and $\mathrm{MgH} 2+5$ wt. \% MWCNT

(ball-to-powder mass ratio of 40:1) with a pressure of 30 bar. For the mixture of $\mathrm{MgH}_{2}$ with $1 \%$ MWCNT the HRBM time was $6 \mathrm{~h}$ and $1.5 \mathrm{~h}$ for $5 \% \mathrm{MWCNT}$.

Another study carried out by Verón et. al. ${ }^{16}$ verified the effect of the co-addition of $\mathrm{Co}+\mathrm{MWCNT}$ to the $\mathrm{MgH}_{2}$ also processed in high energy conditions with very long milling time of about $50 \mathrm{~h}$. In this case, in addition to the evident destruction of the nanotubes, the $\mathrm{MgH}_{2}$ became nanocrystalline, which significantly improved the absorption capacity of hydrogen (about 6.5\%). The concomitant addition of Co to MWCNT promoted a further refinement of the mixture.

The comparison with these works indicates that the mixture of $\mathrm{MgH}_{2}+\mathrm{MWCNT}$ is quite promising to be used as a catalyst even in cases where the milling time is long, although the milling conditions are different.

Figure 5 shows the best results of hydrogen capacity obtained for $\mathrm{MgH}_{2}$ milled with 5\%wt. of different catalysts but using the same conditions employed in the present work. The results of niobium oxide, niobate and titanate, both with a one-dimensional structure are obtained from references 13 and 14. The fastest kinetic results were attained for the $\mathrm{MgH}_{2}-\mathrm{MWCNT}$ system. However, the hydrogen uptake was around 2\% wt lower than $\mathrm{MgH}_{2}$ - niobate for both hydrogen absorption and desorption results. a)

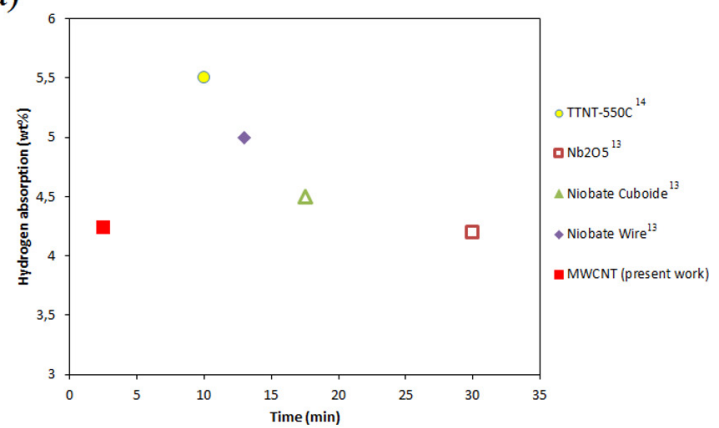

b)

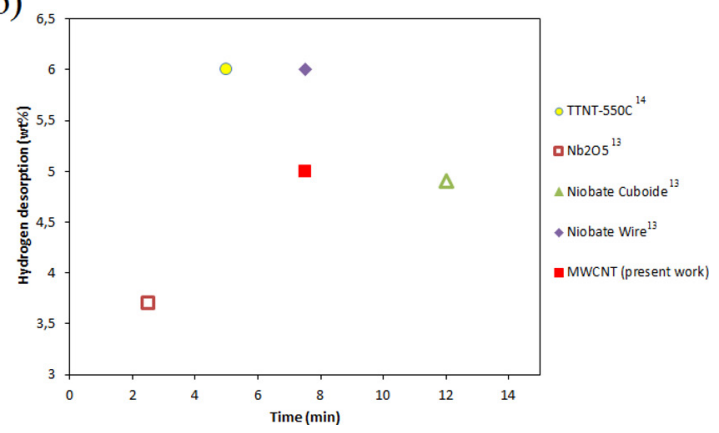

Figure 5. Comparison between the absorption (a) and desorption (b) of hydrogen obtained with $5 \mathrm{wt} . \%$ of different materials milled with magnesium hydride at $350 \mathrm{C}$

The effect of using carbon materials with different structures on $\mathrm{MgH}_{2}$ decomposition was studied and the carbon nanotubes showed better results than graphite and activated carbon. So the ones that do not have a 1-D morphology showed the worst results and therefore contributes to interpret these findings mentioned previously ${ }^{6}$. Besides the catalytic properties of those materials, it seems as if the one-dimensional morphology facilitates the hydrogen diffusion.

\section{Final Considerations}

The observed effect of $\mathrm{MgH}_{2}+\mathrm{MWCNT}$ was more effective than other types of carbon-based catalysts. This can be attributed to the morphology and distribution of MWCNT catalysts. However, further studies to elucidate this effect are underway in our research.

\section{Conclusions}

Multi-walled carbon nanotubes (MWCNT) were used as catalysts to enhance hydrogen sorption and were milled only for $20 \mathrm{~min}$ with pre-milled $\mathrm{MgH}_{2}$ The kinetics tests carried out with $\mathrm{MgH}_{2}+5$ wt. $\%$ MWCNT, showed a fast kinetics when comparing to other one-dimensional (1-D) catalysts studied previously and this result can help to emphasize the importance of the catalysts morphology acting as diffusion channels in hydrogen sorption process. 


\section{Acknowledgements}

The authors thank the financial support of FAPERJ and $\mathrm{CNPq}$ and also thank Federal University of Minas Gerais for the carbon nanotubes samples.

\section{References}

1. Share K, Westover A, Li M, Pint CL. Surface engineering of nanomaterials for improved energy storage - A review. Chemical Engineering Science. 2016;154:3-19.

2. David E. An overview of advanced materials for hydrogen storage. Journal of Materials Processing Technology. 2005;162163:169-177.

3. Yao X, Wu C, Du A, Zou J, Zhu Z, Wang P, et al. Metallic and Carbon Nanotube-Catalyzed Coupling of Hydrogenation in Magnesium. Journal of the American Chemical Society. 2007;129(50):15650-15654.

4. Chuang YS, Hwang SJ. Synthesis and hydrogen absorption/ desorption properties of $\mathrm{Mg}-\mathrm{Nb}_{2} \mathrm{O}_{5}-\mathrm{SWCNT} / \mathrm{MWCNT}$ nanocomposite prepared by reactive milling. Journal of Alloys and Compounds. 2016;656:835-842.

5. Popilevsky L, Skripnyuk VM, Beregovsky M, Sezen M, Amouyal Y, Rabkin E. Hydrogen storage and thermal transport properties of pelletized porous $\mathrm{Mg}-2 \mathrm{wt} . \%$ multiwall carbon nanotubes and $\mathrm{Mg}-2 \mathrm{wt} . \%$ graphite composites. International Journal of Hydrogen Energy. 2016;41(32):14461-14474.

6. Lillo-Ródenas MA, Guo ZX, Aguey-Zinsou KF, Cazorla-Amorós D, Linares-Solano A. Effects of different carbon materials on $\mathrm{MgH}_{2}$ decomposition. Carbon. 2008;46(1):126-137.

7. Wu CZ, Wang P, Yao X, Liu C, Chen DM, Lu GQ, et al. Effect of carbon/noncarbon addition on hydrogen storage behaviors of magnesium hydride. Journal of Alloys and Compounds. 2006;414(1-2):259-264.
8. Züttel A, Sudan P, Mauron P, Kyobayashi T, Emenenrgger C, Schlapbach L. Hydrogen storage in carbon nanostructures. International Journal of Hydrogen Energy. 2002;27(2):203-212.

9. Hwang SJ, Chuang YS. Enhanced hydrogen storage properties of $\mathrm{MgH}_{2}$ co-catalyzed with zirconium oxide and singlewalled carbon nanotubes. Journal of Alloys and Compounds. 2016;664:284-290.

10. Yuan J, Zhu Y, Li Y, Zhang L, Li L. Effect of multi-wall carbon nanotubes supported palladium addition on hydrogen storage properties of magnesium hydride. International Journal of Hydrogen Energy. 2016;39(19):10184-10194.

11. Su W, Zhu Y, Zhang J, Liu Y, Yang Y, Mao Q, et al. Effect of multi-wall carbon nanotubes supported nano-nickel and $\mathrm{TiF}_{3}$ addition on hydrogen storage properties of magnesium hydride. Journal of Alloys and Compounds. 2016;669:8-18.

12. Pierard N, Fonseca A, Colomer JF, Bossuot C, Benoit JM, Van Tendeloo G, et al. Ball milling effect on the structure of singlewall carbon nanotubes. Carbon. 2004:42(8-9):1691-1697.

13. Brum MC, da Conceição MOT, Jardim PM, dos Santos DS. The use of one-dimensional Niobate to improve $\mathrm{MgH}_{2}$ hydrogen sorption. Journal of Alloys and Compounds. 2013;615(Suppl 1):S698-S701.

14. Jardim PM, da Conceição MOT, Brum MC, dos Santos DS. Hydrogen sorption kinetics of ball-milled $\mathrm{MgH}_{2}-\mathrm{TiO}_{2}$ based $1 \mathrm{D}$ nanomaterials with different morphologies. International Journal of Hydrogen Energy. 2015;40(47):17110-17117.

15. Lototskyy M, Sibanyoni JM, Denys RV, Williams M, Pollet BG, Yartys VA. Magnesium-carbon hydrogen storage hybrid materials produced by reactive ball milling in hydrogen. Carbon. 2013;57:146-160.

16. Verón MG, Troiani H, Gennari FC. Synergetic effect of Co and carbon nanotubes on $\mathrm{MgH}_{2}$ sorption properties. Carbon. 2011;49(7):2413-2423. 